\title{
Generation of reactive oxygen species by a sufficient, insufficient and varicose vein wall
}

\author{
Wirginia Krzyściak ${ }^{1,2}$ and Mariusz Kózka ${ }^{3}$ \\ 'Department of Radioligand, Chair of Pharmacobiology, Jagiellonian University Medical College, Faculty of Pharmacy, Kraków, Poland; ${ }^{2}$ Depart- \\ ment of Medical Diagnostics, Jagiellonian University Medical College, Faculty of Pharmacy, Kraków, Poland; ${ }^{3}$ Department of General Surgery, \\ Jagiellonian University Medical College, Kraków, Poland
}

\begin{abstract}
Despite numerous theories, the etiology and pathogenesis of primary varicose veins remain unclear. The etiology of chronic venous diseases (CVDs) known as chronic venous insufficiency (CVI) is related to leukocyte trapping. Leukocyte trapping involves trapping of white cells in vessel walls followed by their activation and translocation outside the vessel. Release of reactive oxygen species (ROS) from trapped white cells has been documented. Superoxide dismutase (SOD) directly inhibits the generation of free radicals and compounds that are produced during oxidation by ROS, such as malonyldialdehyde (MDA). The aim of this study was to determine the involvement of free radicals in the etiology of venous changes. The following material was used for the study: fragments of sufficient or insufficient venous system and varices from 31 patients diagnosed with chronic venous disease in the 2nd or 3rd degree, according to clinical state, etiology, anatomy and pathophysiology (CEAP), which were qualified for surgical procedure. The levels of oxidative stress markers strongly correlated with lesions observed by USG in insufficient and varicose veins. In both a higher concentration of MDA was observed, which is a sign of lipid peroxidation. Antioxidative mechanisms, SOD activity and total antioxidative power expressed as FRAP were inversely proportional to MDA concentration. In insufficient and varicose veins both FRAP and SOD activities were significantly lower than in normal veins. The severity of clinical changes was inversely dependent on the efficiency of scavenging of ROS, which additionally proves the participation of free radicals in pathogenesis of CVDs.
\end{abstract}

Keywords: varicose vein, oxidative stress, superoxide dismutase

Received: 25 August, 2010; revised: 23 November, 2010; accepted: 21 February, 2011; available on-line: 07 March, 2011

\section{INTRODUCTION}

In Western Europe, varicose veins are included in the most frequently occurring syndromes in women and men, $65 \%$ and $50 \%$, respectively. Varices are placed second in relation to the prevalence of CVI syndromes concerning women and men, $25-33 \%$ and $10-20 \%$, respectively (e.g., Slagsvold et al., 2009; Egyetem \& Orvostudomanyi, 2010).

Nevertheless, the etiology of varicose veins remains unclear. Some probable factors leading to the development of VVs have been reported. One such factor is dysfunction of vascular endothelium, which could be a result of excessive generation of reactive oxygen species (ROS), depletion of antioxidant defense and oxidative stress development (Yasim et al., 2008). Among other factors, inflammatory processes (Bergan et al., 2008) and release of proinflammatory cytokines have been mentioned (Fig. 1) (Mangiafico et al., 1997).

Under physiological conditions, generation of ROS in the cell is controlled by antioxidant defense enzymes. Most important amongst these are superoxide dismutase (SOD), which catalyze the dismutation of superoxide to hydrogen peroxide, and catalase (CAT), which together with glutathione peroxidase (GPx) converts hydrogen peroxides to water and oxygen (Halliwell \& Gutteridge, 2000). In the case of depletion or inactivation of these enzymes overproduction of superoxide anions, hydroxyl radicals or hydrogen peroxide occurs. These ROS may lead to the destruction of lipid membranes, proteins and other molecules in the endothelium. In turn, ROS stimulate the release of proinflammatory cytokines from damaged endothelial cells. These destructive effects may be attenuated by leukocytes that are trapped and activated in the venous walls.

The etiology of chronic venous disease (CVD), also known as CVI, is related to leukocyte trapping. Leukocyte trapping consist of trapping of white cells in vessel walls, their activation and translocation outside the vessel, resulting in increased blood viscosity and elevated blood flow resistance. These symptoms are manifested by increased endothelial permeability and escape of fluids, circumvascular edema and capillary stenosis (Valencia et al., 2001).

Many authors have studied the influence of anoxia (resulting from blood stagnation) on the interactions between the epithelium and multinuclear macrophages, monocytes, and neutrophils during saphenous vein perfusion (Matić et al., 2000). Those studies showed the adhesion of multinuclear cells to anoxic epithelium of

e-mail address: wirginiakrzysciak@cm-uj.krakow.pl

Abbreviations: AUR, alantoin and uric acid; BCS, bathocuproine disulfonate; BHT, butylated hydroxytoluene; BSA, bovine serum albumin; CAT, catalase; CEAP, clinical state, etiology, anatomy and pathophysiology; CVDs, chronic venous diseases; CVI, chronic venous insufficiency; DETAPAC, diethylenetriaminepentaacetic acid; FRAP, ferric reducing ability of plasma; FRs, free radicals; GPx, glutathione peroxidase; GSV, great saphenous vein; MDA, malonyldialdehyde; NBT/BCS, nitroblue tetrazolium/bathocuproine disulfonate disodium salt; ROS, reactive oxygen species; SFJ, saphenofemoral junction; SOD, superoxide dismutase; TBA, thiobarbituric acid; TPTZ, 2,4,6-Tris(2-pyridyl)-s-triazine; VVs, varicose veins 


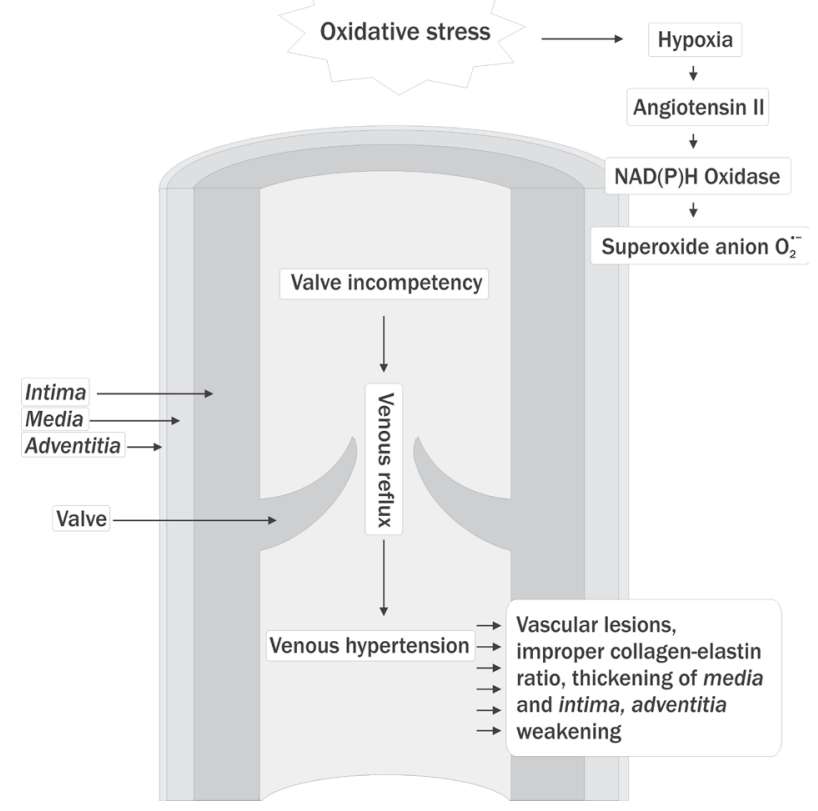

Figure 1. Mechanisms that may contribute to varicose vein formation

varices and insufficient veins is much stronger than for sufficient fragments. This phenomenon may be responsible for the activation of multinuclear cells with angiotensin II, which may later activate $\mathrm{NAD}(\mathrm{P}) \mathrm{H}$ oxidase and potentiate the production of superoxide anion radicals (Fig. 1) (Heistad, 2006). These radicals oxidize lipids and, therefore, lead to the depletion of both enzymatic and non-enzymatic antioxidant mechanisms (Cordis et al., 1998).

Formation of $\mathrm{O}_{2}^{-}$and $\mathrm{H}_{2} \mathrm{O}_{2}$ by xanthine oxidase (XO) increased during reperfusion after hypoxia in cardiovascular disease. Development of CVI involves many different stages. Organic peroxides and $\mathrm{H}_{2} \mathrm{O}_{2}$ are promoters of inflammation process of diseases with pro-inflammatory character. It was observed that chronic inflammation could be conducive in the process of carcinogenesis. It was shown that induced granulocytes could damage DNA of neighboring cells. This occurred during inflammation process in various diseases, when phagocytes release ROS not only to phagosomes but also outside the cell. Part of ROS attack foreign objects, against which they are formed; however, remaining ROS are flowing in extracellular fluids where they encounter other cells. In sites, where local inflammatory process is occurring on and many stimulated phagocytes are accumulated, concentrations of released ROS may be high. The inflammatory reaction has a mechanism of positive feedback; exposure of plasma to action of activated phagocytes results in generation of chemotactic factors and activating new lymphocytes (Madamanchi et al., 2005). Generation of chemotactic factors is inhibited by SOD. It might mean that the factor responsible for SOD generation is $\mathrm{O}^{-}{ }_{2}$ (Cooke et al., 2003). Another element of positive feedback during CVI development might be the induction of thrombocytes aggregation by anion radical superoxide and hydrogen peroxide, which in consequence might result in microthrombus formation. A situation is possible, when ROS released in a site of accumulation of huge number of activated phagocytes will damage surrounding tissues by exposing them to strong oxida- tive stress and enzymes. During the course of CVI, an increase in the level of hemosiderin related to iron metabolism is observed. Hemosiderin at physiological concentration protects from ROS. In addition, it captures hemoglobin and hem released from damaged erythrocytes, and inhibits release of Fe ions that can later catalyze Haber-Weiss reaction:

$$
\mathrm{O}_{2}^{-}+\mathrm{H}_{2} \mathrm{O}_{2}{ }^{2+} / \mathrm{Fe}^{3+}
$$

In Haber-Weiss reaction, in the presence of free iron ions, with the participation of reactive biologically partially reduced oxygen forms $\left(\mathrm{O}_{2}^{-}\right.$and $\left.\mathrm{H}_{2} \mathrm{O}_{2}\right)$, an $\mathrm{OH} \bullet$ free radical is formed, which can react with every biological molecule being in its direct neighborhood.

$$
\begin{aligned}
& \mathrm{Fe}^{2+}+\mathrm{H}_{2} \mathrm{O}_{2} \rightarrow \mathrm{Fe}^{3+}+\mathrm{OH}^{-}+\mathrm{OH} \\
& \mathrm{Fe}^{3+}+\mathrm{O}_{2}^{-} \rightarrow \mathrm{Fe}^{2+}+\mathrm{O}_{2}
\end{aligned}
$$

This $\mathrm{OH} \bullet$ radical may initiate separation of hydrogen atom from polyunsaturated fatty acids $(\mathrm{LH})$ or result in peroxidation of lipids of cell membranes, whose oxidative forms are strongly cytotoxic.

$\mathrm{OH} \bullet+\mathrm{LH} \rightarrow \mathrm{H}_{2} \mathrm{O}+\mathrm{L}^{\circ}$
$\mathrm{L}^{\circ}+\mathrm{LH} \rightarrow \mathrm{LOO}^{\circ}$
$\mathrm{LOO}^{\circ}+\mathrm{LH} \rightarrow \mathrm{LOOH}+\mathrm{L}^{\circ}$

Lipid hydroperoxides $(\mathrm{LOOH})$ are accumulated, and in the presence of free iron ions they can initiate additional lipid peroxidation.

$$
\begin{aligned}
& \mathrm{Fe}^{2+}+\mathrm{LOOH} \rightarrow \mathrm{Fe}^{3+}+\mathrm{LO}^{\circ}+\mathrm{OH}^{-} \\
& \mathrm{LO}^{\circ}+\mathrm{LH} \rightarrow \mathrm{LOH}+\mathrm{L}^{\circ}
\end{aligned}
$$

These reactions have a cascade mechanism. The $\mathrm{OH} \bullet$ radical is strictly reactive, its cytotoxic effect also concerns DNA molecules, causing breaks in DNA strands (forming 8-hydroxy-2'-deoxyguanosine) (Oliński \& Jurgowiak, 2002).

In case of CVI, a relationship can be noticed between the level of oxidative DNA damages and the level of iron ions localized in the tissues. Such observations were made by Jabłońska and Krzyściak (2010), where they noticed increased level of Fe concentration in varicose veins in comparison to sufficient vessels, $30.9 \%$ and $197.16 \%$, respectively. In these studies, average concentration of iron significantly increased in insufficient venous vessels (from 54.4 ( \pm 43.9) to 64.8) and varicose veins (from $70.7( \pm 46.9)$ to 90.1). These observations can be explained by the function, which is played by iron in CVI condition. This increase was significantly correlated with oxidative DNA damages of blood lymphocytes of CVI patients, which was observed by Krzyściak et al. (2010). This can be explained by growing concentration of free iron catalyses changes during Haber-Weiss reaction, in which $\mathrm{OH} \bullet$ is formed. Huge amount of hydroxyl radical results in disorders of tissue functions, cells damage, destruction of proteins, lipids, carbohydrates as well as DNA. It has influence on oxidative stress, being one of the causes of CVI.

\section{THE AIM OF THE STUDY}

The aim of the study was to establish the role of free radicals participation in the etiology of vein dysfunction. The study was made to verify hypothesis that one fragment of ischemic, damaged vein can induce further lesions in competent fragment of the same vein. 


\section{MATERIAL}

The material used for the study comprised fragments of sufficient or insufficient venous system and varices from 31 patients (23 women and 8 men aged 26 to 68 years, mean age 49.9 years \pm 12.5 S.D.) with diagnosed chronic venous disease of the 2 nd or 3rd degree, according to the clinical state, etiology, anatomy and pathophysiology (CEAP), which were qualified to undergo surgical procedure.

All participants underwent a medical interview, physical examinations, and duplex sonography. The symptoms of chronic venous disease had been observed for more than one year in all patients. Biochemical examinations, morphology, coagulation parameters were performed in all patients before the surgical procedure (Table 1).

Consents were obtained from all patients, and the study procedure was approved by the Bioethical Committee of the Jagiellonian University (KBET/125/B/2007).

During the operation, entire trunk of the great saphenous vein (GSV) (from ankle to groin) was extracted. The part located near medial ankle was considered suf-

Table 1. Characteristic of patients $(n=31)$ with varicose veins participating in the study.

\begin{tabular}{|c|c|c|c|}
\hline & Mean \pm S.D. & Min & Max \\
\hline Age (years) & $50 \pm 13$ & 23 & 68 \\
\hline $\mathrm{RBCs} \times 10^{6} / \mu \mathrm{L}$ & $4.6 \pm 0.3$ & 4.0 & 5.2 \\
\hline $\mathrm{Hb}$ g/dcL & $13.7 \pm 0.8$ & 11.8 & 15.6 \\
\hline Hct \% & $41.3 \pm 2.3$ & 34.5 & 45.2 \\
\hline $\mathrm{PLTs} \times 10^{3} / \mu \mathrm{L}$ & $238 \pm 58$ & 132.0 & 371.0 \\
\hline $\mathrm{WBC} s \times 10^{3} / \mu \mathrm{L}$ & $6.4 \pm 2.0$ & 3.6 & 14.3 \\
\hline $\mathrm{HDL} \mathrm{mM}$ & $1.1 \pm 0.3$ & 0.6 & 1.7 \\
\hline Chol mM & $5.5 \pm 1.1$ & 4.0 & 7.8 \\
\hline TG mM & $2.8 \pm 1.5$ & 0.6 & 5.0 \\
\hline LDL mM & $4.0 \pm 1.0$ & 2.0 & 5.8 \\
\hline Glu mM & $5.4 \pm 1.3$ & 4.4 & 10.9 \\
\hline PT \% & $93.8 \pm 14.4$ & 71.5 & 132.0 \\
\hline INR & $1.0 \pm 0.1$ & 0.9 & 1.5 \\
\hline APTT s & $29.8 \pm 3.2$ & 22.6 & 35.5 \\
\hline Fibr g/L & $3.5 \pm 0.9$ & 2.4 & 6.2 \\
\hline
\end{tabular}

APTT - activated partial thromboplastin time; Chol — cholesterol; Fibr - fibrinogen; Glu - glucose; $\mathrm{Hb}$ - hemoglobin; Hct - hematocrit; $\mathrm{HDL}$ - high-density lipoprotein; INR — international normalized ratio; LDL - low-density lipoprotein; PLTs — platelets count; PT — prothrombin time; RBCs - red blood cells count; TG — triglyceride; WBCs — white blood cells count; . ficient in ultrasonographical (USG) examination. Extraction of this part had to be made because of varicose veins and perforator localization. The insufficient part was extracted from great saphenous vein (GSV) located in saphenofemoral junction (SFJ) where USG showed incompetent valves and massive venous reflux. Tissues after extraction were transported in dry ice and further processed in the laboratory.

\section{METHODS}

Total antioxidant power measurement. Ferric ion reducing ability of plasma (FRAP) was used to determine total antioxidant power according to the method of Benzie et al. (1996). FRAP values were obtained by measuring ferric to ferrous ion reduction at low $\mathrm{pH}(0.3$ $\mathrm{M}$ acetate buffer, $\mathrm{pH}$ 3.6) coupled with tripyridyltriazine oxidation, whose absorbance was measured at $593 \mathrm{~nm}$.

Tissues were minced in four volumes of $0.05 \mathrm{M}$ phosphate buffer, pH 7.8, using Ultra Turrax T25 basic ultraspeed tissue grinder $(8 \times 5 \mathrm{~s}$ bursts $)$. All procedures were performed on ice. The homogenates were centrifuged at $1000 \times \mathrm{g}$ for $15 \mathrm{~min}\left(0-4^{\circ} \mathrm{C}\right)$. The resultant supernatant was drawn and the pellet was discarded.

Aliquote of $0.1 \mathrm{ml}$ of each sample was mixed with $3 \mathrm{ml}$ of reagent mixture $(25 \mathrm{ml}$ of acetate buffer $(300$ $\mathrm{mM}, \mathrm{pH}$ 3.6), $0.25 \mathrm{ml}$ 2,4,6-Tris(2-pyridyl)-s-triazine (5 $\mathrm{mM}$ TPTZ) in $40 \mathrm{mM} \mathrm{HCl}$, and $0.25 \mathrm{ml}$ ferric solution $\left(20 \mathrm{mM} \mathrm{FeCl}_{3}\right)$ in distilled water). The reagent mixture was always freshly prepared. FRAP value was calculated by preparing an aqueous solutions of known $\mathrm{Fe}^{\mathrm{II}}$ concentration, in the range of $0-1000 \mu \mathrm{M}\left(\mathrm{FeSO}_{4} \cdot 7 \mathrm{H}_{2} \mathrm{O}\right)$. The blank contained FRAP reagent mixture. Reactions were performed for $5 \mathrm{~min}$ at $37^{\circ} \mathrm{C}$. FRAP values were expressed in mmol per milligram of protein.

Enzymatic antioxidant investigation. SOD activity was measured by the method of Spitz and Oberley, (1989). Homogenates of veins were used. The catalytic conversion of xanthine to uric acid and $\mathrm{O}_{2}{ }^{--}$by xanthine oxidase provides an initial constant flux of superoxide in a PBS (phosphate-buffered saline) at room temperature. NBT reduction by $\mathrm{O}_{2}{ }^{-}$to the blue formazan was followed at $560 \mathrm{~nm}$ in a Marcel Media (Poland) spectrophotometer at room temp. The rate of NBT (Nitroblue tetrazolium) reduction in the absence of tissue was used as the reference rate $(0.020 \pm 0.005$ absorbance $/ \mathrm{min})$. When increasing amounts of protein (containing SOD activity) were added to the system, the rate of NBT reduction was progressively inhibited. The degree of inhibition was defined as the percentage of the reference rate of NBT reduction when SOD activity was not present. The data were plotted as percentage inhibition vs protein concentration. One unit of activity was defined as the amount of protein causing $50 \%$ inhibition. The assay mixture also contained catalase to remove $\mathrm{H}_{2} \mathrm{O}_{2}$ and diethylenetriaminepentaacetic acid (DETAPAC) to chelate metal ions capable of redox cycling and interfering with the assay system. The measurements were performed spectrophotometrically using a Marcel Media spectrophotometer.

Aliquote of $0.1 \mathrm{ml}$ of each supernatant was mixed with $0.8 \mathrm{ml}$ of reagent mixture containing: bovine serum albumin (BSA) and DETAPAC in $50 \mathrm{mM}$ potassium phosphate buffer, $\mathrm{pH}$ 7.8, $1 \mathrm{mM}$ DETAPAC, 0.13 $\mathrm{mg} / \mathrm{ml} \mathrm{BSA}(12.90 \mathrm{ml}), 1.0 \mathrm{U}$ bovine liver catalase $(0.5$ $\mathrm{ml}), 56 \mu \mathrm{M}$ nitroblue tetrazolium (NBT) $(0.5 \mathrm{ml}), 0.1$ $\mathrm{mM}$ xanthine $(1.7 \mathrm{ml}), 0.05 \mathrm{M}$ potassium phosphate buffer $(0.3 \mathrm{ml}), 50 \mu \mathrm{M}$ bathocuproine disulfonate disodium 
(BCS) salt $(0.1 \mathrm{ml})$ and $0.1 \mathrm{ml}$ of xanthine oxidase $(13.2$ $\mathrm{U} / \mathrm{ml}$ ) to achieve the required reference rate. The reagent mixture was always freshly prepared.

All data were expressed in units of SOD activity per milligram of protein.

Determination of lipid peroxidation. Oxidative stress and lipid peroxidation have been implicated as important mechanisms for chemical-induced cell injury/death and the development of numerous diseases. Malondialdehyde (MDA) is a product of lipid peroxidation that appears to be produced in relatively constant proportion from the breakdown of polyunsaturated fatty acids. MDA was quantified according to the method of Buege and Aust (1978) based on thiobarbituric acid (TBA) reactivity. The sufficient, insufficient and varicose vein homogenates were used in the study and quantification of MDA was done by reaction with TBA and measurement of the pink chromophore produced.

An aliquote of $0.5 \mathrm{ml}$ of each sample was mixed with $1 \mathrm{ml}$ of reagent mixture prepared by diluting the stock solution containing: $30 \mathrm{~g}$ trichloroacetic acid (15\% final), $4.16 \mathrm{ml}$ concentrated $\mathrm{HCl}(0.2 \mathrm{~N}$ final), $0.74 \mathrm{~g}$ thiobarbituric acid $(0.37 \%$ final $), \mathrm{H}_{2} \mathrm{O}$ to 0.2 liter. The stock solution (TCA/HCl/TBA) was heated to $70^{\circ} \mathrm{C}$ and stored one month in $4{ }^{\circ} \mathrm{C}$. Before use (TCA/ $\mathrm{HCl} / \mathrm{TBA}$ ) was dissolved in water four times to yield a working solution.

Butylated hydroxytoluene (BHT) in ethanol was added to a final concentration of $0.03 \%$. Working solution was prepared daily and continually stirred with a magnetic stir bar. After shaking, the tube was placed into a boiling water bath for 15 min. After cooling in cold water, the resulting chromogen was extracted with $3 \mathrm{ml}$ of $\mathrm{n}$ butyl alcohol by shaking vigorously for $1 \mathrm{~min}$. Separation of the organic phase was facilitated by centrifugation at $1000 \times g$ for $10 \mathrm{~min}$. The TBA-MDA adduct was quantified using fluorescence emission at $553 \mathrm{~nm}$ with excitation at $532 \mathrm{~nm}$. The concentration of TBA-MDA adduct was calculated from a standard curve between 0 and 50 nmol MDA/sample using 1,1,3,3-tetramethoxypropane as the standard. MDA concentrations were expressed in $\mathrm{nmol} / \mathrm{mg}$ protein. The measurements were performed using an LS-5 spectrofluorimeter (Perkin-Elmer, USA).

Statistical analysis. Values were expressed as median $( \pm 25$ th $)-75$ th quartile. In the absence of a homogeneity of variance, the non-parametric Friedman test for dependent variables was used.

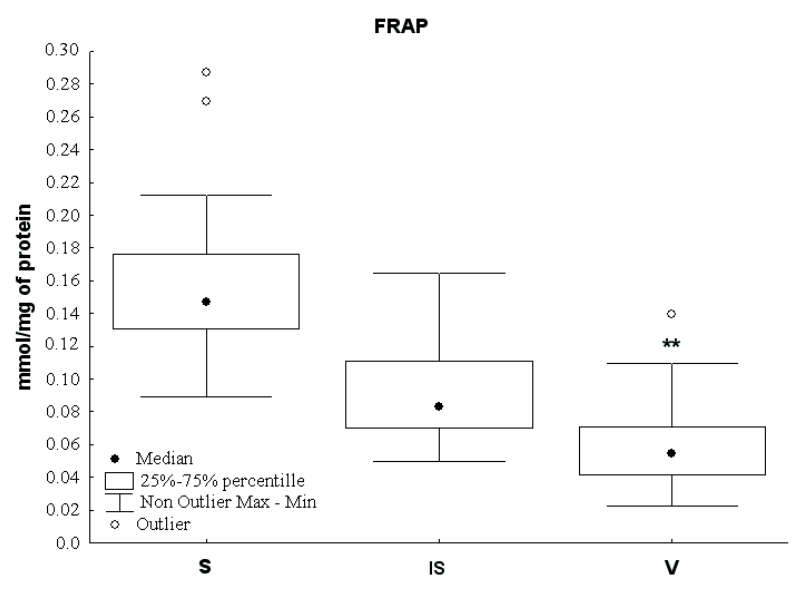

Figure 2. Total antioxidant power expressed as FRAP in various fragments of GSV in patients with chronic venous diseases (S) sufficient veins, (IS) insufficient veins, and (V) varices (**P<0.001; by the ANOVA test).

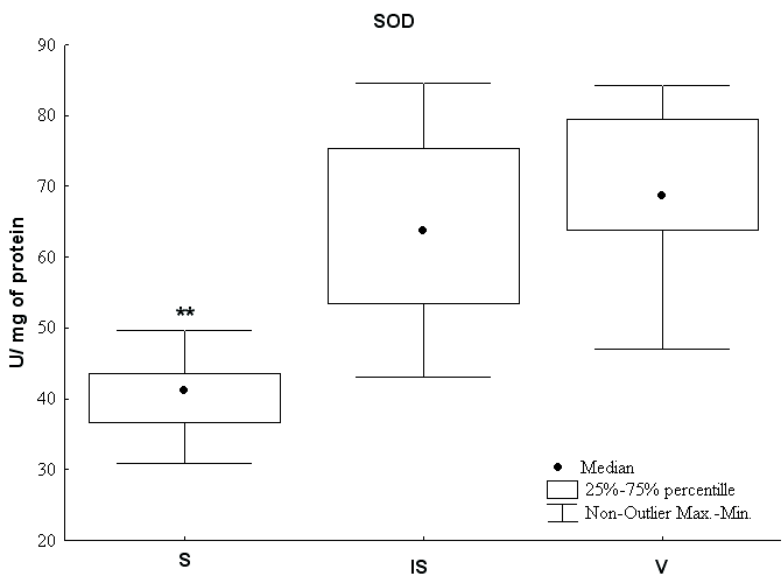

Figure 3. SOD activity in fragments of GSV in patients with chronic venous diseases

(S) sufficient veins, (IS) insufficient veins, and (V) varices $\left({ }^{* *} P<\right.$ 0.001 ; by the ANOVA test).

Statistical analyses were performed with $\mathrm{R}$ v. 2.6.2 (2008) http://www.R.project.org. Graphs were produced with Statistica v. 7.0 PL.

\section{RESULTS}

When the antioxidant power of vein homogenates was qualified the highest value of FRAP was observed for sufficient veins $(0.147( \pm 0.09)-0.27 \mathrm{U} / \mathrm{mg}$ protein $)$ and the lowest one for varices $(0.05( \pm 0.02)-0.1 \mathrm{U} /$ $\mathrm{mg}$ protein) and insufficient veins $(0.08( \pm 0.06)-0.16$ $\mathrm{U} / \mathrm{mg}$ protein). The differences between those values were statistically significant $(P<0.001$; Fig. 2$)$.

The activity of SOD was significantly higher $(P<0.001$; Fig. 3) in homogenates of varices $(68.7( \pm 63.9)-79.5$ $\mathrm{U} / \mathrm{mg}$ protein) and insufficient veins (63.8 ( \pm 53.4$)$ $75.4 \mathrm{U} / \mathrm{mg}$ protein) than in homogenates of sufficient veins (41.2 ( \pm 36.7$)-43.5 \mathrm{U} / \mathrm{mg}$ protein).

The concentration of MDA was significantly higher $(P<0.001$; Fig. 4$)$ in homogenates of varices $(0.48( \pm 0.4)$ - 0.6) and insufficient veins $(0.26( \pm 0.1)-0.5)$ than in homogenates of sufficient veins $(0.06( \pm 0.03)-0.1)$.

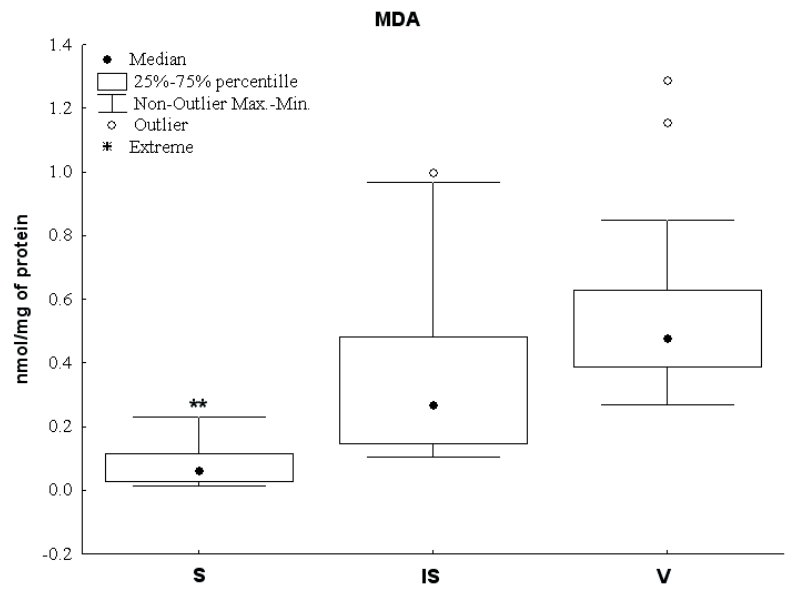

Figure 4. MDA concentrations in various fragments of GSV in patients with chronic venous diseases (S) sufficient veins, (IS) insufficient veins, and (V) varices $\left({ }^{* *} P<0.001\right.$; by the ANOVA test). 


\section{DISCUSSION}

Varicose veins (VVs) of lower limbs are a common vascular insufficiency present in about $20 \%$ of the Western population (Antignani \& Caliumi, 2007). Dysfunction of vascular endothelium has been reported to be the main factor leading to the development of VVs. Furthermore, excessive generation of ROS, depletion of antioxidant defense and oxidative stress development have been found to damage endothelial cells (Yasim et al., 2008). Under physiological conditions generation of ROS is under the control of antioxidant defense enzymes. Here, in the cell the balance between superoxide dismutase (SOD) and catalase (CAT) activities seems crucial; these enzymes, together with glutathione peroxidase (GPx) convert hydrogen peroxides to water and oxygen (Drőge, 2002).

An imbalance between oxidative stress markers MDA generation and SOD activity results in overproduction of ROS, which in turn may lead to the destruction of lipid membranes, proteins and other molecules in the endothelium.

The increased release of MDA contributes to counterbalancing the varicose vein relaxation and to increasing preload in the varicose via MDA-induced venoconstriction. MDA has also been reported to increase release of ROS (Han et al., 2005).

Statistical analysis of the results obtained showed significant differences between mean SOD activities in varicose veins and insufficient veins on the other hand (thigh part of GSV in which USG showed deficiency of venous valves with massive blood reflux) and normal vein (part of vein extracted from malleolus medialis area which showed no pathological changes on USG examination). Those differences were $30 \%$ and $35 \%$, respectively.

Similar results were observed by Mahmound et al., (2002). They pointed towards increased SOD activity in hypoxemic veins in varicose areas, compared to areas considered a normal during USG examination. This activity was almost three times higher than activities reported for competent veins.

This phenomenon can be explained by local hydrostatic hypertension resulting from varicose veins, which probably can activate many types of adhesion molecules (e.g., selectins, integrins- $\beta_{1}$ and $\beta_{2}$ ) and many intercellular-type adhesion molecules (e.g., ICAM-1 and VCAM1) as well as increase their receptor expression. This leads to an increased leukocyte migration from varicose veins (incompetent part extracted from the GSV). After reaching high ICAM-1 and VCAM-1 expression, leukocytes do not revert to their starting location (Peschen et al., 1999). Many phenomena connected with ROS liberation, increased adhesion and increased expression of gp100MEL-14 receptor occur in trapped leukocytes (Kishimoto et al., 1989). This leads to an increased migration of inflammatory cells to damaged tissue. In our research we tested one of the products, malondialdehyde (MDA), that is formed from cell lipids exposed to ROS. We observed statistically significant differences between MDA concentration and total antioxidant status (TAS) measured as the ferric reducing ability of plasma (FRAP) in sufficient, insufficient and varicose veins. The MDA concentration was inversely proportional to FRAP. The highest MDA concentration (lowest FRAP) was observed in varicose and insufficient veins.

Similar conclusions were reached by Ellerton and Stacey (2003) who measured 8-izoprostane concentra- tions (also one of lipid peroxidation products) and total amount of antioxidants. They found that 8-izoprostane level was significantly higher in varicose and insufficient veins in comparison to veins that showed no pathological changes in USG examination. That fact suggested increased lipid peroxidation in varicose veins.

A high level of reactive oxygen species (ROS) was observed in local varicose areas. This was also confirmed by our research and by other authors. Flore et al. (2003) found a higher ROS level in blood samples taken from lower limbs of patients with varicose veins than in those from healthy volunteers.

These results confirm that a patients suffering from chronic venous insufficiency are constantly under oxidative stress. Their TAS is lowered and lipid peroxidation level (measured as MDA concentration) increased.

Our observations correlate with the ones discussed in the literature. Numerous researchers draw attention to a key role of inflammation - which is the mechanism responsible for CVI progression and its symptoms (Nicolaides, 2005). It was amply demonstrated that activation markers in venous endothelium and leukocytes during CVI (e.g., Glowiński \& Glowiński, 2002; Bergan, 2007). Interaction between leukocytes and endothelium (which results in toxic metabolites e.g., MDA; Rojas \& Phillips, 1999 ) is promoted by slow venous flow (Danielsson et al., 2003). Mahmound et al. (2002) found strong lipid peroxidation (increased MDA concentration) around insufficient venous valves (compared to normal noninflamed vessels). This phenomenon was also confirmed in our research. Also Tryankina et al. (2003) drew attention to decreased amount of plasma antioxidants and increased lipid peroxidation in patients with varicose veins in comparison to healthy individuals. All this shows how strongly oxidative stress can decrease defense mechanisms of patients witch CVI (Wlaschek et al., 2005).

Research by James et al. (2003), in which alantoin and uric acid (AUR) concentration were assayed in homogenized vein tissues of ten patients with CVI, documented that AUR concentration was five times higher than normal, indicating high oxidative stress induced by neutrophils. It is worth mentioning that FRAP assay in those patients did not show any significant differences with the controls - unlike our research in which we found significantly higher FRAP in normal vessels in comparison to varicose/insufficient veins.

In oxidative stress environment — an inflamed tissue SOD acts as an antioxidant converting reactive biologically partially reduced oxygen forms $\left(\mathrm{O}_{2}^{-}\right.$and $\left.\mathrm{H}_{2} \mathrm{O}_{2}\right)$ into inactive compounds. In both varicose vein areas and insufficient veins, SOD activity is higher than in competent veins. Clinical symptoms and morphological lesions are proportional to this SOD efficiency. This also proves that ROS take part in varicose vein development.

In the presence of reactive biologically partially reduced oxygen forms $\left(\mathrm{O}_{2}^{-}\right.$and $\left.\mathrm{H}_{2} \mathrm{O}_{2}\right)$, an $\mathrm{OH} \bullet$ free radi$\mathrm{cal}$ is formed, which can react with every biological molecule being in its direct neighborhood.

$\mathrm{Fe}^{2+}+\mathrm{H}_{2} \mathrm{O}_{2} \rightarrow \mathrm{Fe}^{3+}+\mathrm{OH}^{-}+\mathrm{OH} \cdot$
$\mathrm{Fe}^{3+}+\mathrm{O}_{2}^{-} \rightarrow \mathrm{Fe}^{2+}+\mathrm{O}_{2}$

This $\mathrm{OH} \bullet$ radical may initiate separation of hydrogen atom from polyunsaturated fatty acids $(\mathrm{LH})$ or result in peroxidation of lipids of cell membranes, whose oxidative forms are strongly cytotoxic.

$\mathrm{OH} \bullet+\mathrm{LH} \rightarrow \mathrm{H}_{2} \mathrm{O}+\mathrm{L}^{\circ}$

$\mathrm{L}^{\circ}+\mathrm{LH} \rightarrow \mathrm{LOO}^{\circ}$ 
$\mathrm{LOO}^{\circ}+\mathrm{LH} \rightarrow \mathrm{LOOH}+\mathrm{L}^{\circ}$

Lipid hydroperoxides $(\mathrm{LOOH})$ are accumulated, and in the presence of free iron ions they can initiate additional lipid peroxidation.

$\mathrm{Fe}^{2+}+\mathrm{LOOH} \rightarrow \mathrm{Fe}^{3+}+\mathrm{LO}^{\circ}+\mathrm{OH}^{-}$

$\mathrm{LO}^{\circ}+\mathrm{LH} \rightarrow \mathrm{LOH}+\mathrm{L}^{\circ}$

CVI is also accompanied by increased lipid peroxidation (high MDA concentration - product of lipid peroxidation) and dysfunction of antioxidant defense mechanisms. The decreased amounts of antioxidants in pathological veins result in increased risk of ROS-induced cell and DNA damage. This damage, once done and not repaired, causes tissue remodeling, comprises white muscle cell integrity and, consequently, CVI progression and complications.

Assaying chosen pro- and anti-oxidant markers: MDA concentration, TAS (FRAP) and SOD activity can be useful to help determine the severity of venous lesions in CVI patients.

Our research provides novel insights in two different, but overlapping areas. First, all parameters we researched: antioxidant enzyme activity, TAS and FRAP bring us to a conclusion that the main reason behind CVI is antioxidative system dysfunction. Second, we believe that recognition of the role of oxidative stress in the development of chronic diseases implicates clinical actions and modification of treatment. Further research is needed to discover efficient means of lowering oxidative stress. For a practicing physician, information that oxidative stress takes part in varicose vein development can have a crucial influence on the therapy he/she applies. Also simple modification of the patients diet and lifestyle can have beneficial effects

\section{CONCLUSIONS}

The course of chronic venous disease progresses with intensified oxidative stress in blood plasma and tissues of insufficient veins and varices in comparison to veins unchanged by inflammatory process.

Measurement of chosen oxidative and antioxidative markers in addition to other commonly used methods may be helpful in determining vessel lesions in patients with CVD.

The severity of clinical changes is dependent on the efficiency of ROS scavenging, which additionally proves the participation of free radicals in the pathogenesis of CVD.

\section{Acknowledgements}

We would like to thank Grzegorz Kazek from the Radioligand Department for technical assistance.

This work was supported by the Jagiellonian University Programs No. W1/K/ZBW/000488.

\section{REFERENCES}

Benzie F, Iris F, Strain JJ (1996) The ferric reducing ability of plasma (FRAP) as a measure of "antioxidant power": the FRAP assay. Anal Biochem 239: 70-76.

Bergan J (2007) Molecular mechanisms in chronic venous insufficiency. Ann V asc Surg 21: 260-266.

Bergan JJ, Pascarella L, Schmid-Schönbein GW (2008) Pathogenesis of primary chronic venous disease: Insights from animal models of venous hypertension. J V asc Surg 47: 183-192.
Buege JA, Aust SD (1978) Microsomal lipid peroxidation. Method Enzymol 53: 302-310.

Cooke M, Evans M, Dizdaroglu M (2003) Oxidative DNA damage: mechanism, mutation and disease. FASEB J 17: 1195-1214.

Cordis GA, Das DK, Riedel W (1998) High-performance liquid chromatographic peak identification of 2,4-dinitrophenylhydrazine derivatives of lipid peroxidation aldehydes by photodiode array detection. J Chromatogr A 798: 117-123.

Danielsson G, Norgren L, Truedsson L, Andreasson A, Danielsson P, Nilsson A, Swartbol P (2003) Flavonoid treatment in patients with heale venous ulcer: flow cytometry analysis suggests increased CD11b expression on neutrophil granulocytes in the circulation. Vasc Med 8: 83-88.

Drôge W (2002) Free radicals in the physiological control of cell function. Physiol Rev 82: 47-95.

Egyetem S, Orvostudomanyi A (2010) Chronic venous disease. A state of art. Orv Hetil. 151: 131-139.

Flore R, Santoliquido A, Antonio DL, Pola E, Flex A, Pola R, Gallinella Muzi M, Farinon A, Rulli F, Gaetani E et al. (2003) Long saphenous vein stripping reduces local level of reactive oxygen metabolites in patients with varicose disease of the lower limbs. World J Surg 27: 473-475.

Glowiński J, Glowiński S (2002) Generation of reactive oxygen metabolite by the varicose vein wall. Eur J Vasc Endovasc Surg 23: $550-555$.

Halliwell B, Gutteridge JMC (2000) Free radicals in biology and medicine. 3rd edn. Oxford University Press.

Han L-N, Gu Y, Liu F-G (2005) Function of vasodilating and vasoconstricting factors in the pathogenesis of varicose vein. Chinese J Clin Rehab 9: 116-117.

Heistad DD (2006) Oxidative stress and vascular disease: 2005 Duff Lecture. Arterioscler Thromb Vasc Biol 26: 689-695.

Jabłońska P, Krzyściak W et al. (2010) Oxidative stress in patients with CVD. Central European Congress Life Sciences, Krakow, Poland.

James TJ, Hughes MA, Cherry GW, Taylor RP (2003) Evidence of oxidative stress in chronic venous ulcers. Wound Rep Reg 11: 172-176.

Kishimoto TK, Jutila MA, Berg EL, Butcher EC (1989) Neutrophil Mac-1 and MEL-14 adhesion proteins inversely regulated by chemotactic factors. Science 245: 1238-1241.

Krzyściak W et al. (2010) Oxidative DNA damage in blood of CVD patients taking Detralex. Central European Congress Life Sciences, Krakow, Poland.

Wali MA, Suleiman SA, Kadoumi OF, Nasr MA (2002) Superoxide radicals concentration and superoxide dismutase (SOD) enzyme activity in varicose vein. Ann Thorac Cardiovasc Surg 8: 286-290.

Madamanchi N, Vendrov A, Runge M (2005) Oxidative stress and vascular disease. Arterioscler Thromb V asc Biol 25: 29-38.

Mangiafico RA, Malatino LS, Santonocito M, Spada RS, Benedetto FA (1997) Plasma endothelin-1 release in normal and varicose saphenous veins. Angiology 48: 769-774.

Matić M, Duran V, Ivkov-Simić M, Poljacki M, Gajinov Z, Begenisić M (2000) Microcirculatory changes in chronic venous insufficiency Med Pregl 53: 579-583.

Nicolaides A (2005) Chronic venous disease and leukocyte-endothelium interaction: from symptoms to ulceration. Angiology 56: 11-19.

Oliński R, Jurgowiak M (2002) Iron metabolizm, oxidative DNA damage and atherosclerosis. Acta Angiologia 8: 37-44.

Peschen M, Lahaye T, Hennig B, Weyl A, Simon JC, Vanscheidt W (1999) Expression of the adhesion molecules ICAM-1, VCAM-1, LFA-1 and VLA-4 in the skin is modulated in progressing stages of chronic venous insufficiency. Acta Derm Venereol 79: 27-32.

R Development Team, R (2008) A Language and Environment for Statistical Computing. R Foundation for Statistical Computing; http:// www.R.project.org. Graphs were produced with Statistica v. 7.0 PL.

Rojas AI, Phillips TJ (1999) Patients witch chronic leg ulcers show diminished levels of vitamins A and E, carotenes and zinc. Dermatol Surg 25: 601-604.

Slagsvold C, Stranden E, Rosales A (2009) Venous insufficiency in the lower limbs. Tidssker Nor Laegeforen 129: 2256-2259.

Spitz DR, Oberley LW (1989) An assay for superoxide dismutase activity in mammalian tissue homogenates. Anal Biochem 15: 8-18.

Tryankina SA, Kolobova OI, Varshavsky BY (2003) Lipid peroxidation in pathogenesis of varix dilatation. Kliniczna Diagdnostyka Laboratoryjna 6: 19-20 (in Polish).

Valencia IC, Falabella A, Kirsner RS, Eaglstein WH (2001) Chronic venous insufficiency and venous leg ulceration. $J$ Am Acad Dermatol 44: 401-421.

Wlaschek M, Scharffetter-Kochanek K (2005) Oxidative stress in chronic vein leg ulcers. Wound Rep Reg 13: 452-454.

Yasim A, Kilinc M, Aral M, Oksuz H, Kabalci M, Eroglu E, Imrek S (2008) Serum concentration of procoagulant, endothelial and oxidative stress markers in early primary varicose veins. Phlebology/Venous Forum of the Royal Society of Medicine. 23: 15-20.

Yeoh-Ellerton S, Stacey MC (2003) Iron and 8-isoprostane levels in acute and chronic wounds. J Invest Dermatol 121: 918-925. 